\title{
Time Trends for Agricultural Crop Production in Saskatchewan, Canada: 1905-2011 圈SIAST
}

\section{Sierra Rayne and Kaya Forest ${ }^{\mathrm{b}}$}

a Chemologica Research, PO Box 74, 318 Rose Street, Mortlach, Saskatchewan, Canada, SOH 3E0; e-mail: rayne.sierra@gmail.com

b Department of Environmental Engineering, Saskatchewan Institute of Applied Science and Technology, Palliser Campus, PO Box 1420,600 6th Avenue NW, Moose Jaw, Saskatchewan, Canada, S6H 4R4; e-mail: kaya.forest@siast.sk.ca

\section{Introduction \\ - Saskatchewan is one of the world's most productive agricultura cropping regions \\ Iltivated farmland is in the \\ Dexport value of crops was $\$ 8.34$ billion in 2008 technical, and engineering knowledve and practientific, affected the amount and type of crops produced over the past}

Methods

crop statistics were obtained from the Government of Saskatchewan Agricultural Statistics online database:

http://www.agriculture.gov.sk.ca/Statistics

Results and Discussion

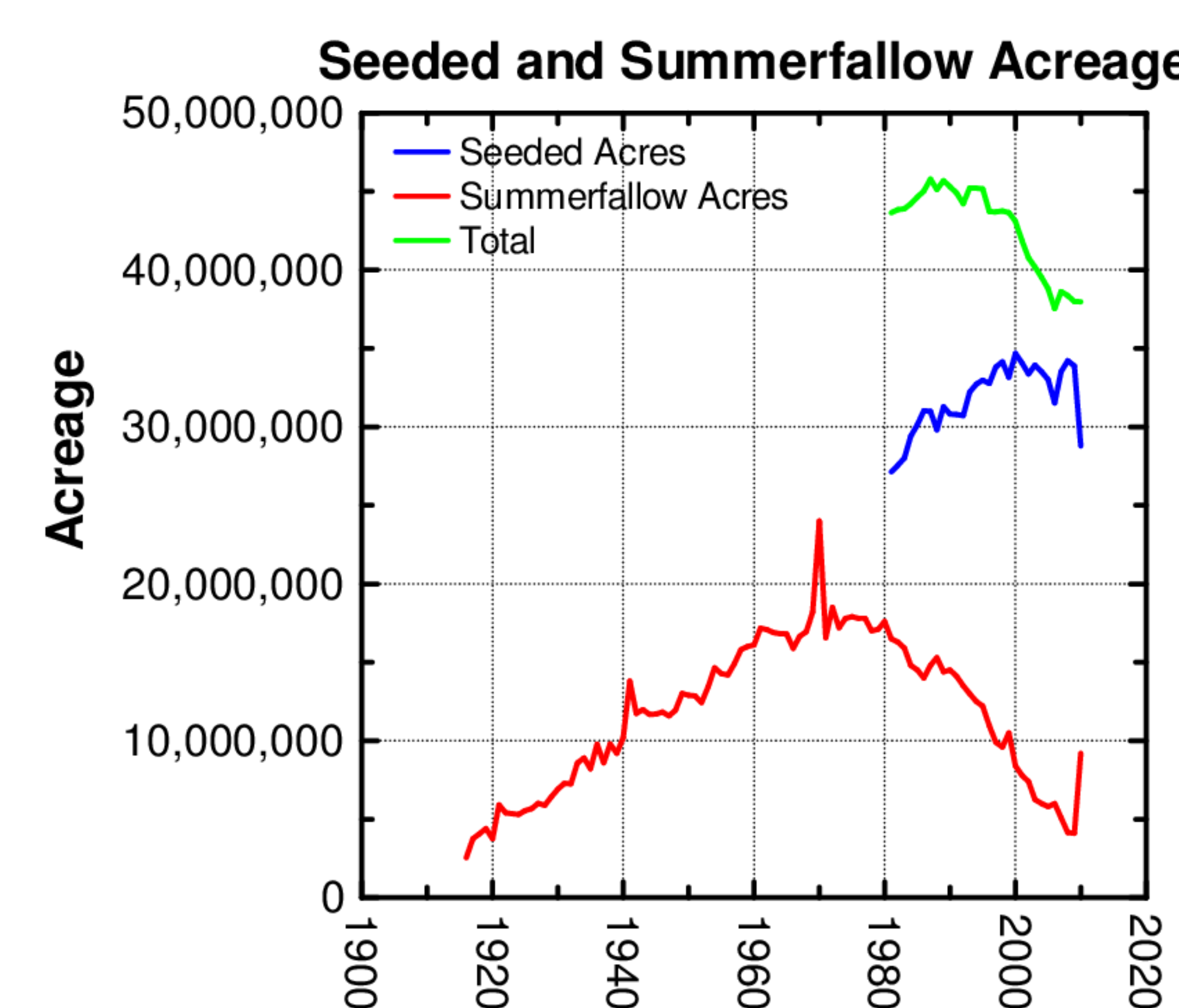

summerfallow acreage increased from the 1910 s through to the late 1960s/early 1970s, then declined to near historic lows by the

- a modest increase over the last year is evident during the 2000 s ased between 1980 and 2000, were stable - during the 2000s, and declined sharply in 2010 slightly during the 1990s, and declined more sharply during the

\section{Results and Discussion}

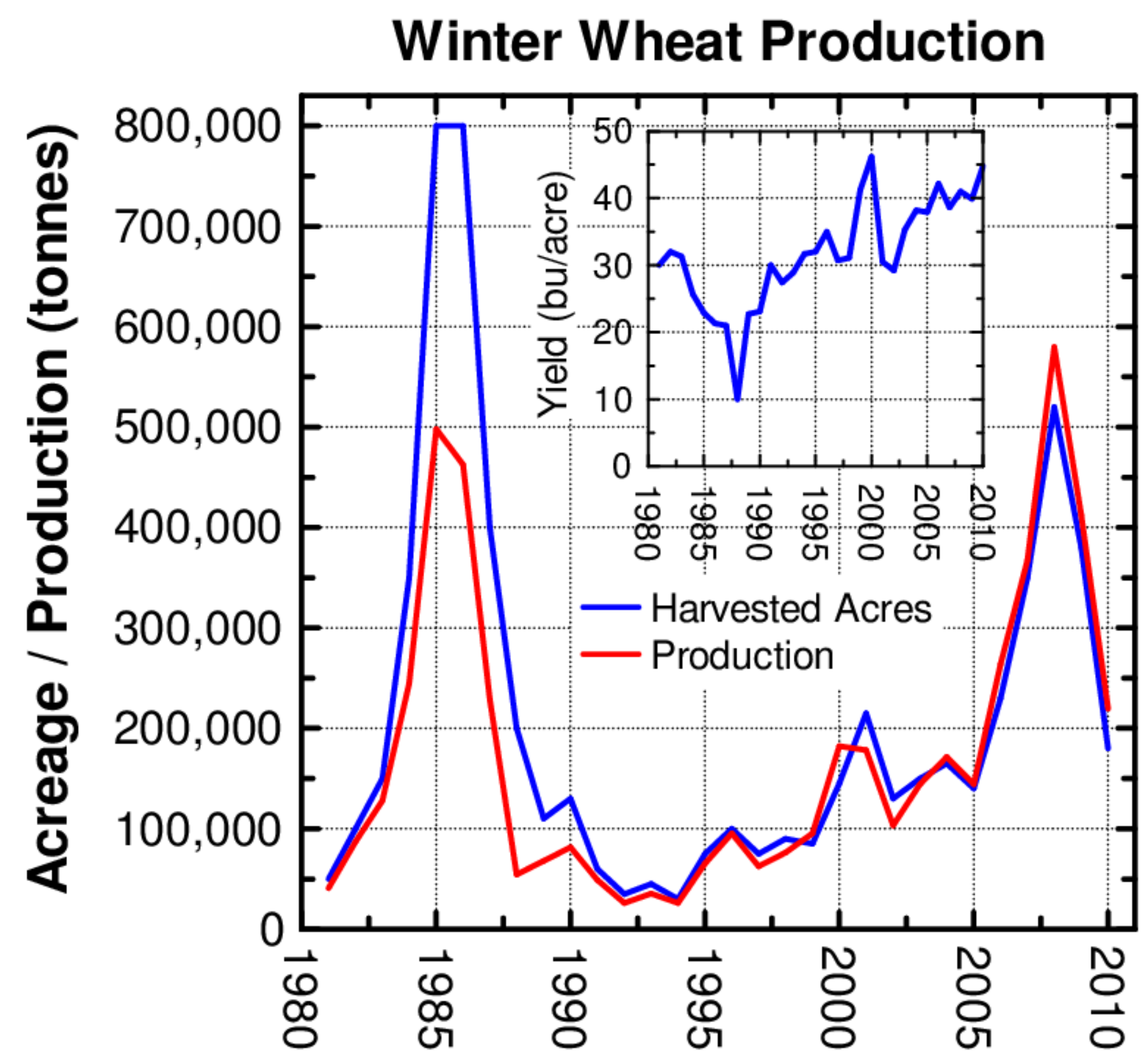

winter wheat acreage/production has been highly variable since yields have increased steadily since the mid-1980

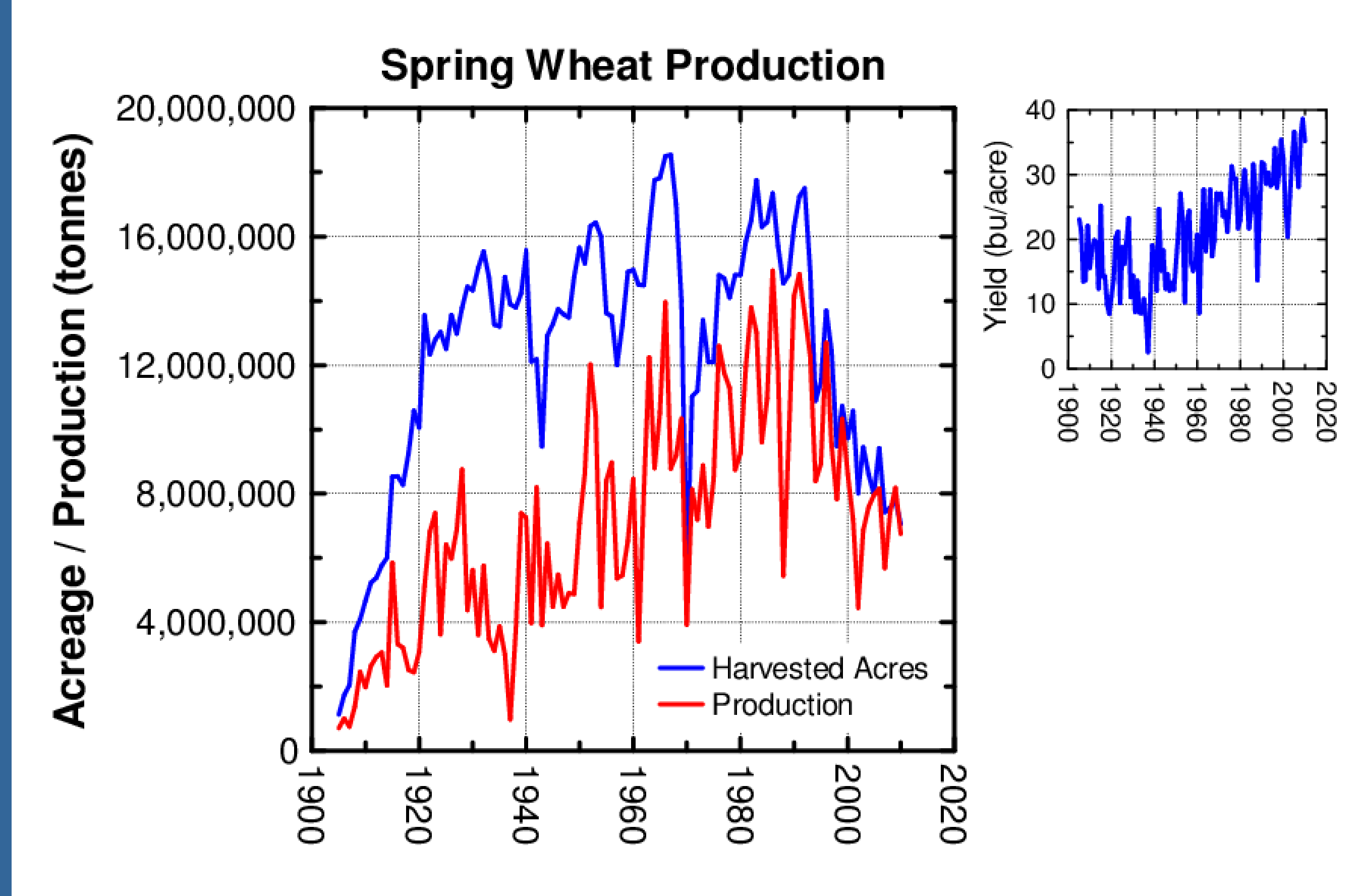

spring wheat acreage/production has been highly variable since spring wheat acreage/production has been highly variable since
the 1900 s, generally increasing up to the late 1980 s/early 1990 s and declining steadily to the present

\section{Results and Discussion}

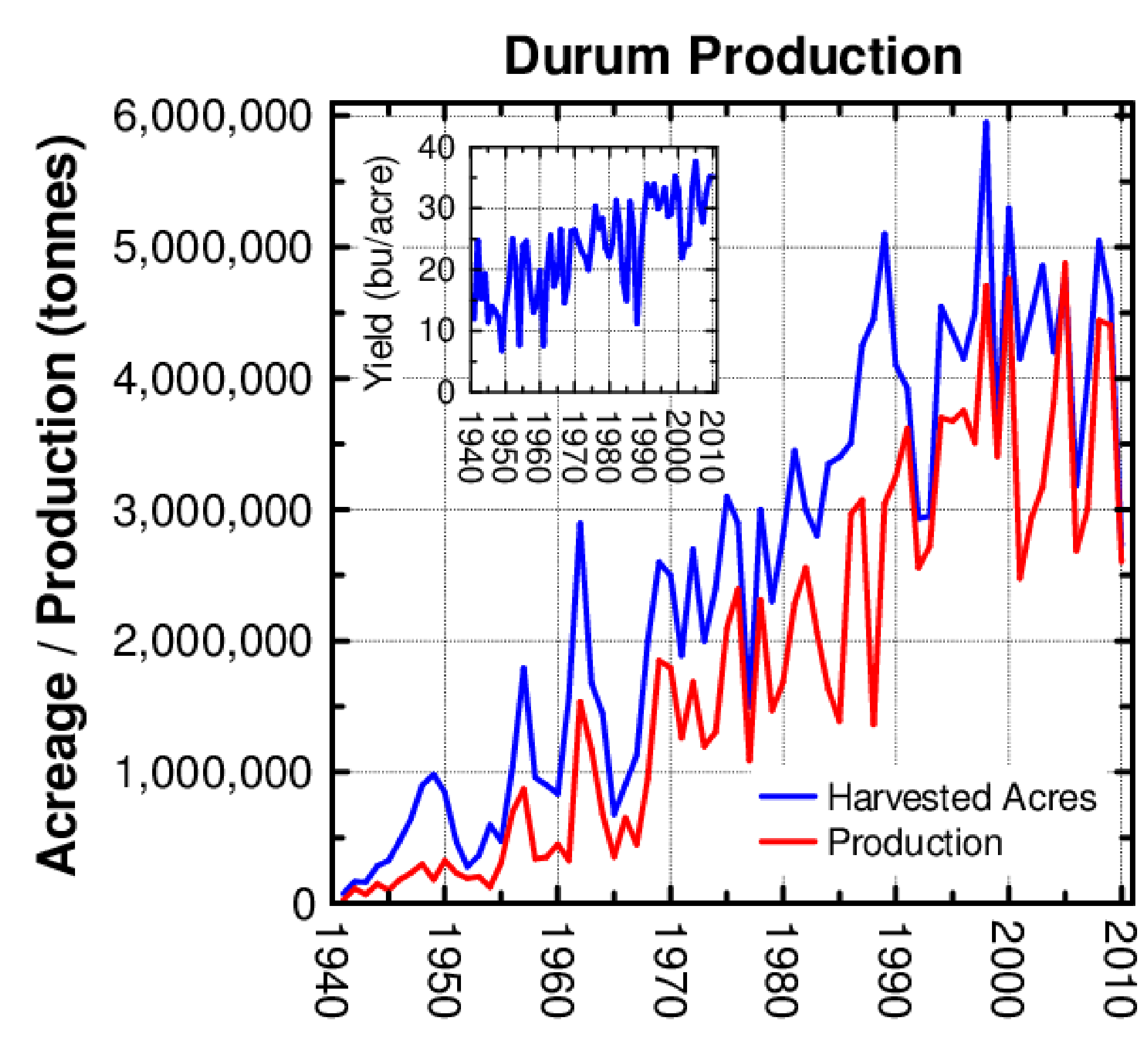

- durum acreage/production increased between the early 1940 s and the late 1990s, and has since levelled off

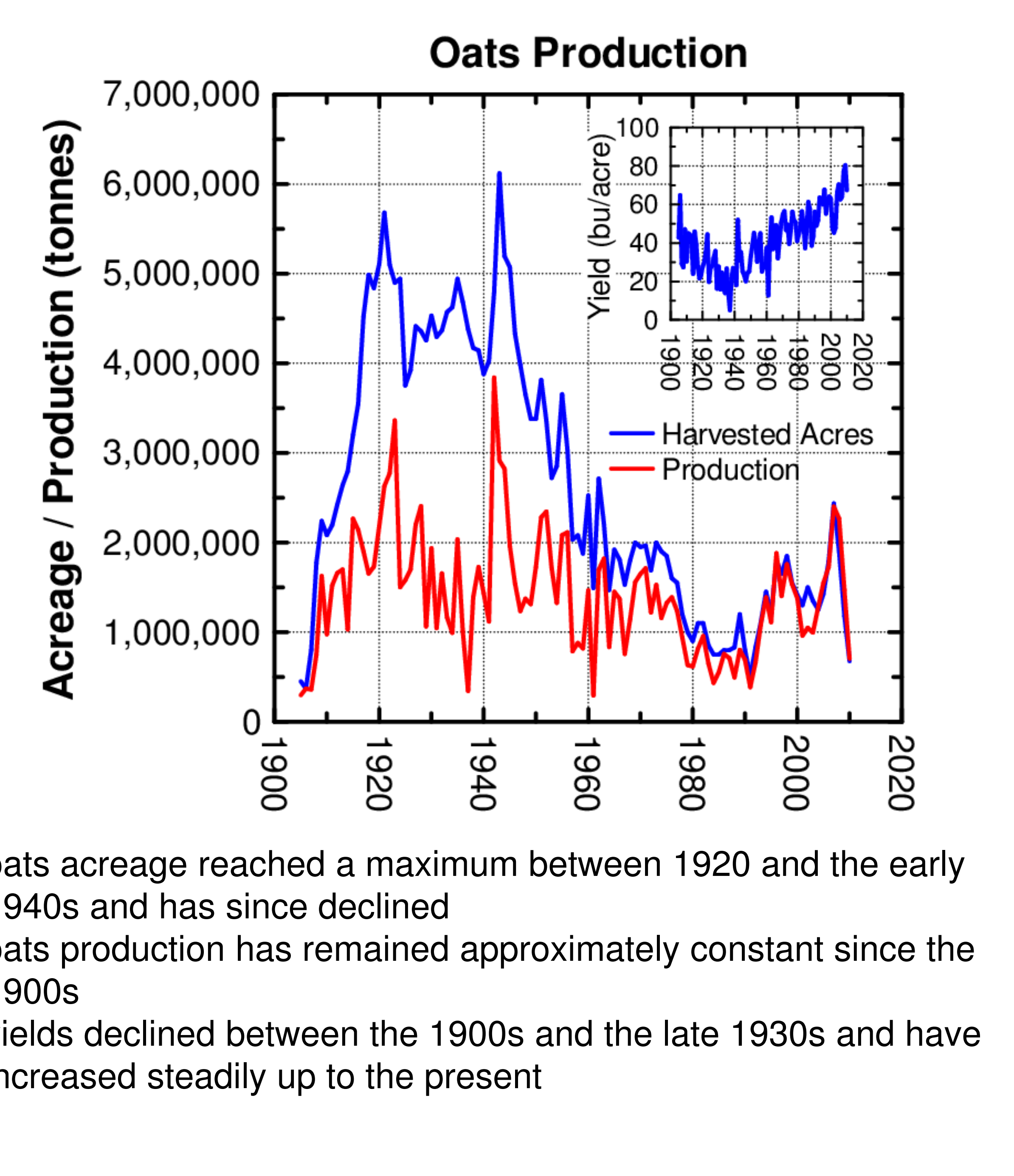

Results and Discussion

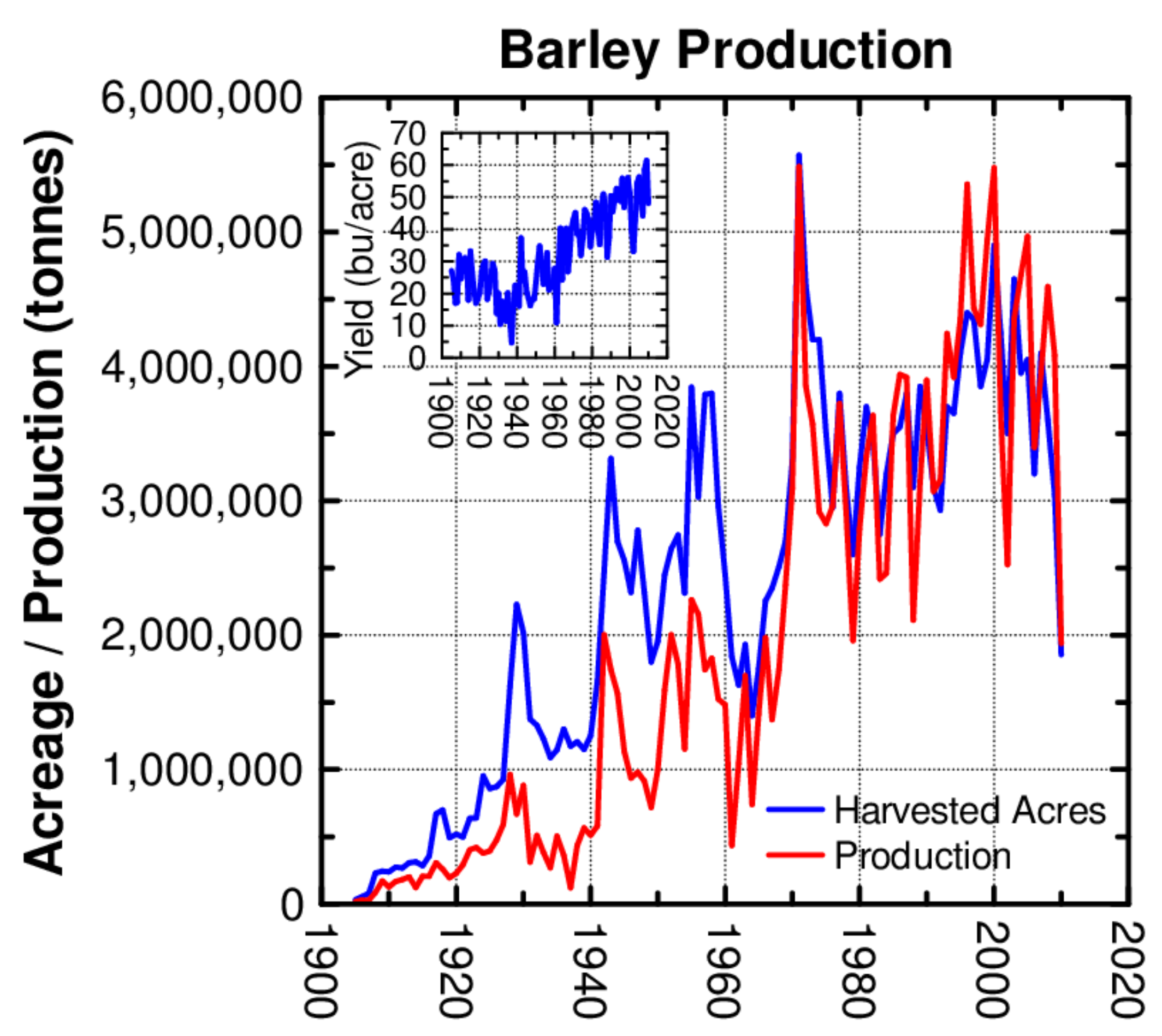

列 declined until the between the 1900s and late 1920s, then up to the present

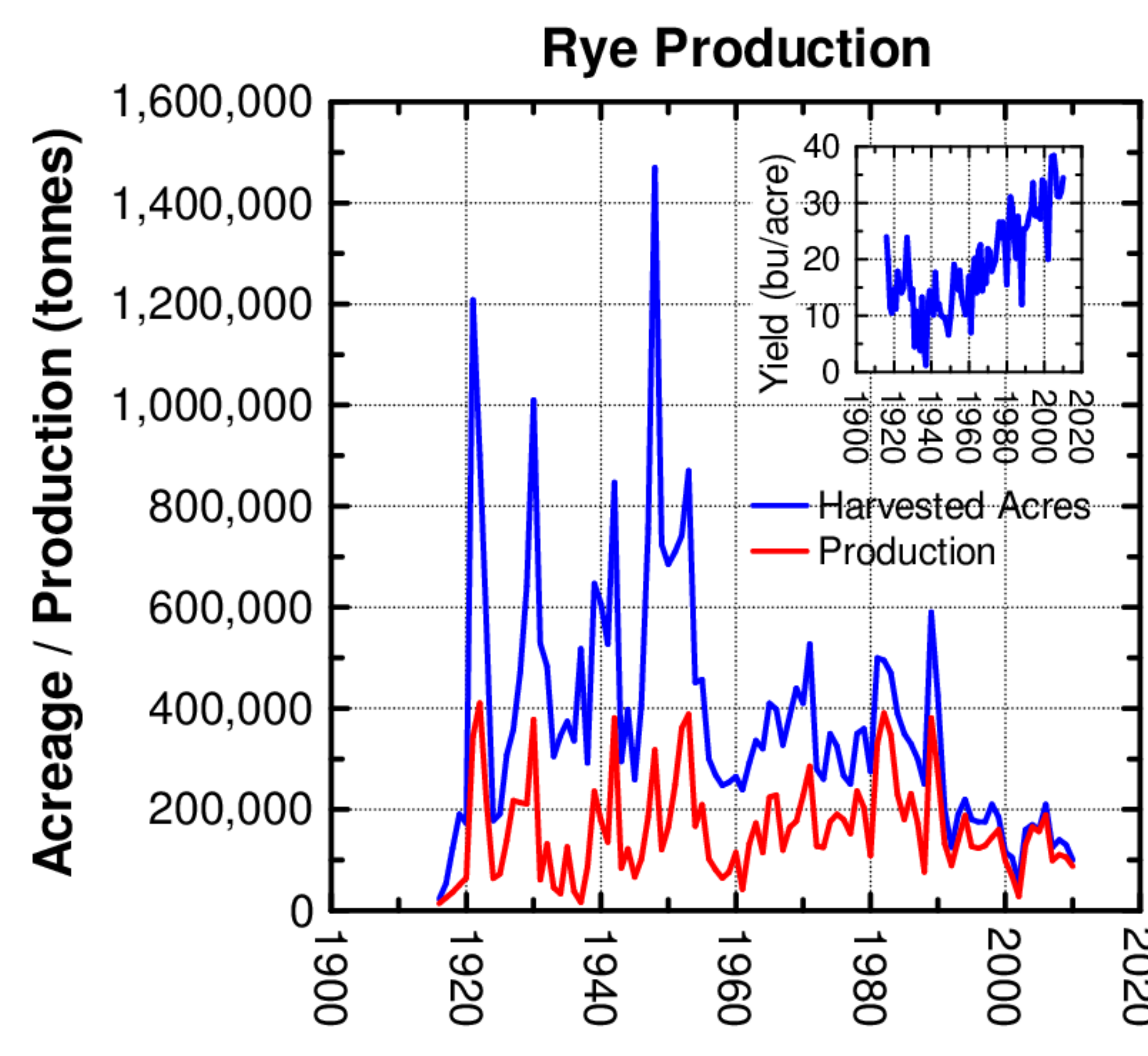

rye acreage/production has been highly variable since the $1910 \mathrm{~s}$ and appears to have remained approximately constant up to the present (although the large acreage peaks that occurred - velds declined betued since increased steadly 


\section{Time Trends for Agricultural Crop Production in Saskatchewan, Canada: 1905-2011 SIAST}

\section{Sierra Rayne a ${ }^{a}$ Kaya Forest ${ }^{b}$}

a Chemologica Research, PO Box 74, 318 Rose Street, Mortlach, Saskatchewan, Canada, S0H 3E0; e-mail: rayne.sierra@gmail.com b Department of Environmental Engineering, Saskatchewan Institute of Applied Science and Technology, Palliser Campus, PO Box 1420,600 6th Avenue NW, Moose Jaw, Saskatchewan, Canada, S6H 4R4; e-mail: kaya.forest@siast.sk.ca

Results and Discussion

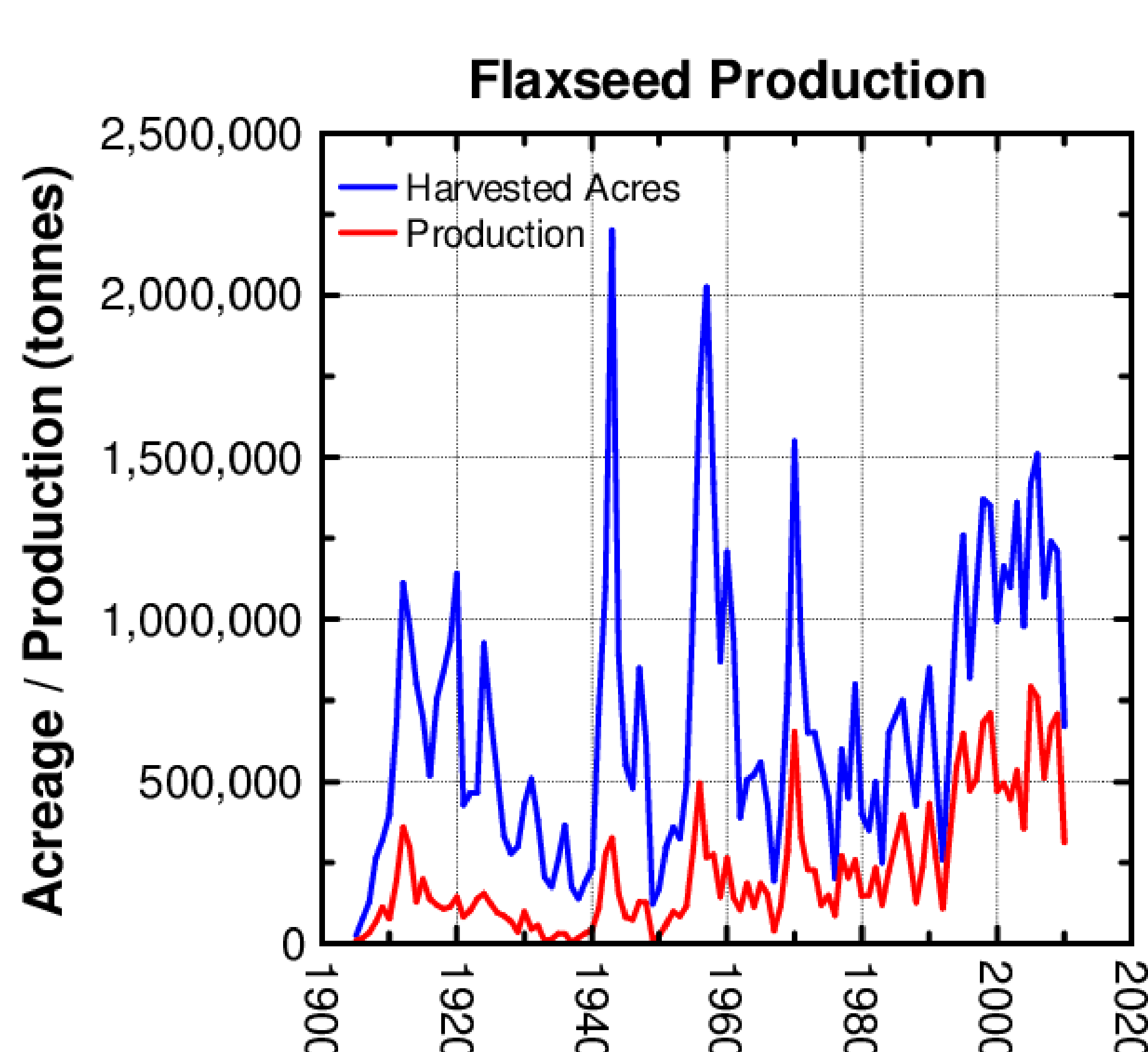

llaxseed acreage/production was highly variable (and with no clear trend) beween hil 1900 s and he late 1970 s, and has

since increased steadily

ween the 1900 s and the late 1930 s and have since increased steadily

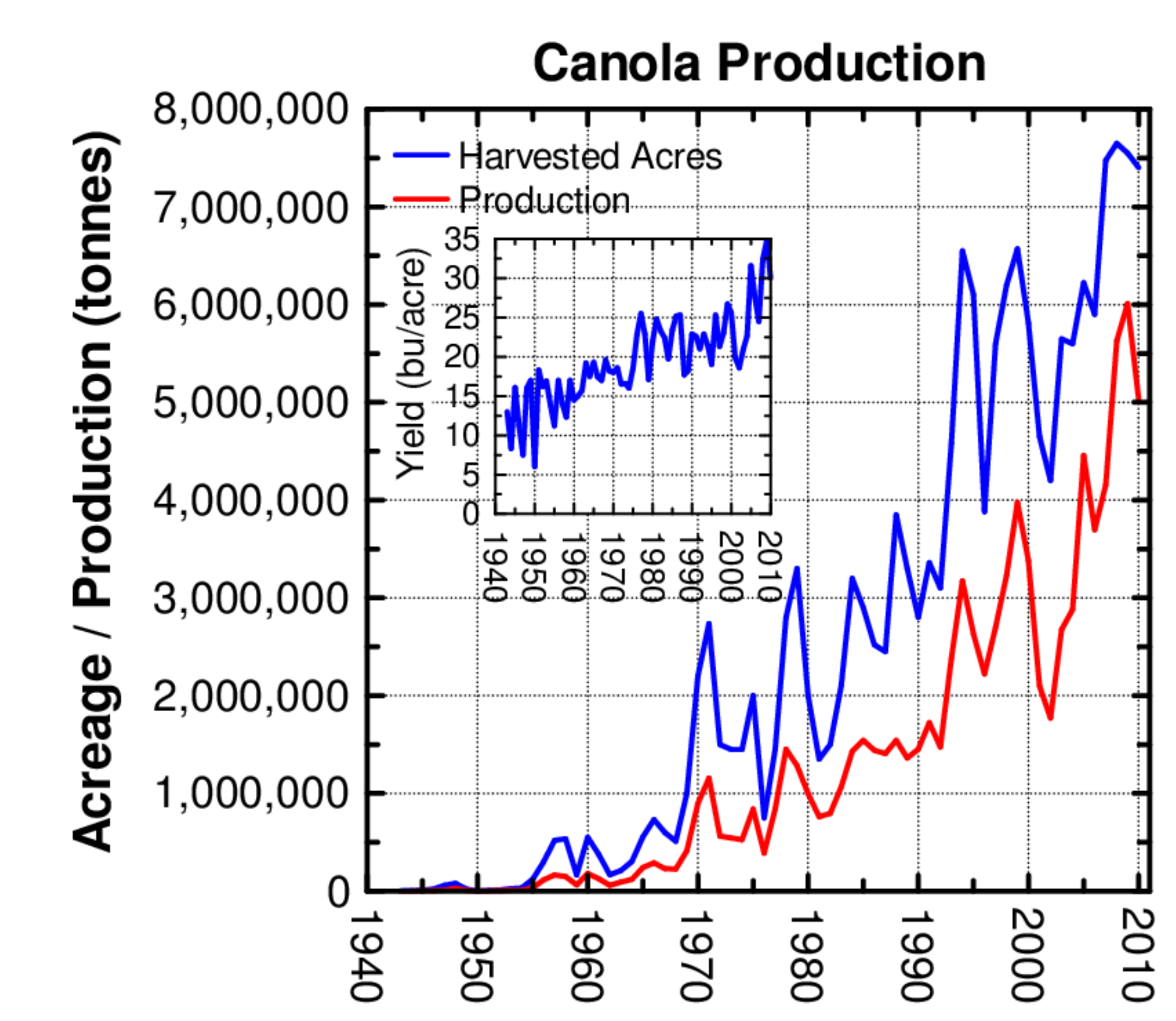

canola acreage/production has been increasing steadily since the 1940 s, as have yields

\section{Results and Discussion}

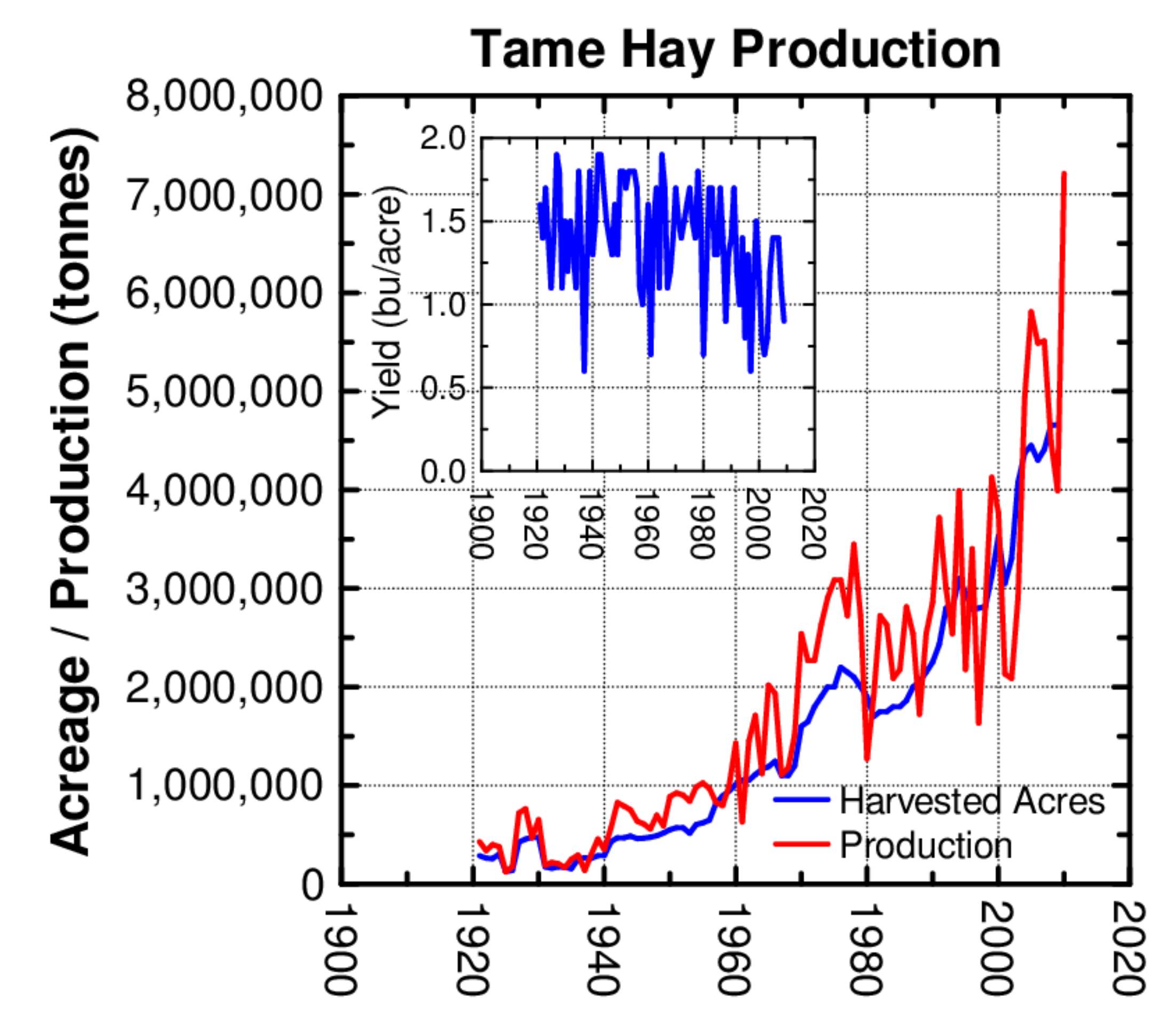

- tame hay acreage/production has been increasing steadily since the 1920 s

Je 1920 s and the early 1990s, and has since declined slightly

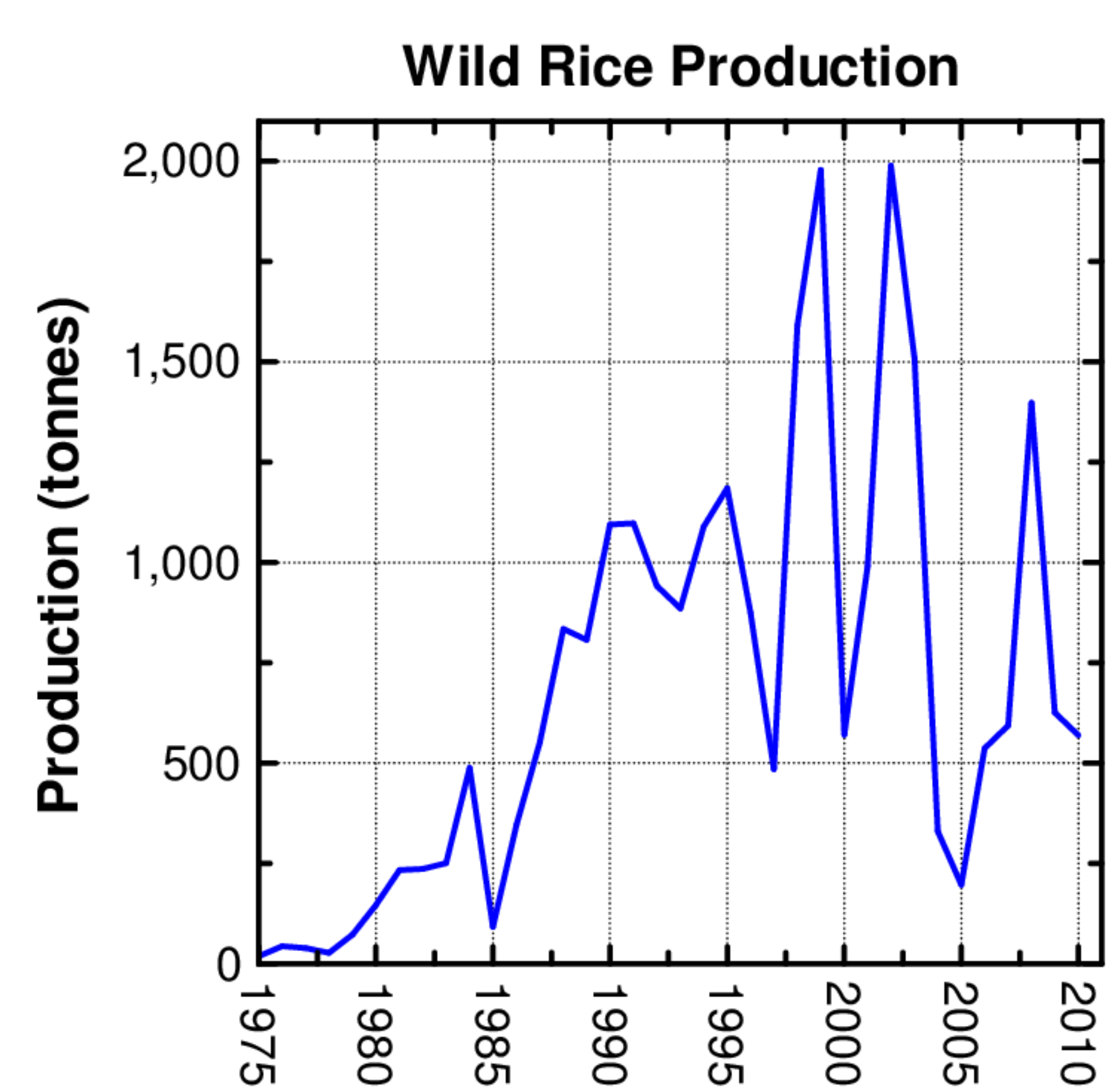

wild rice production rose steadily from the mid-1970s to the mid-

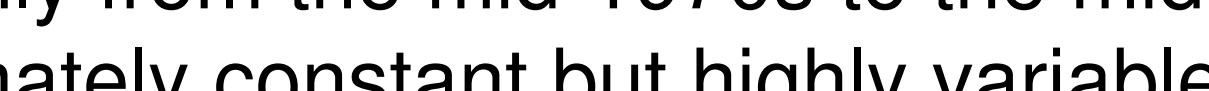
since then

\section{Results and Discussion}

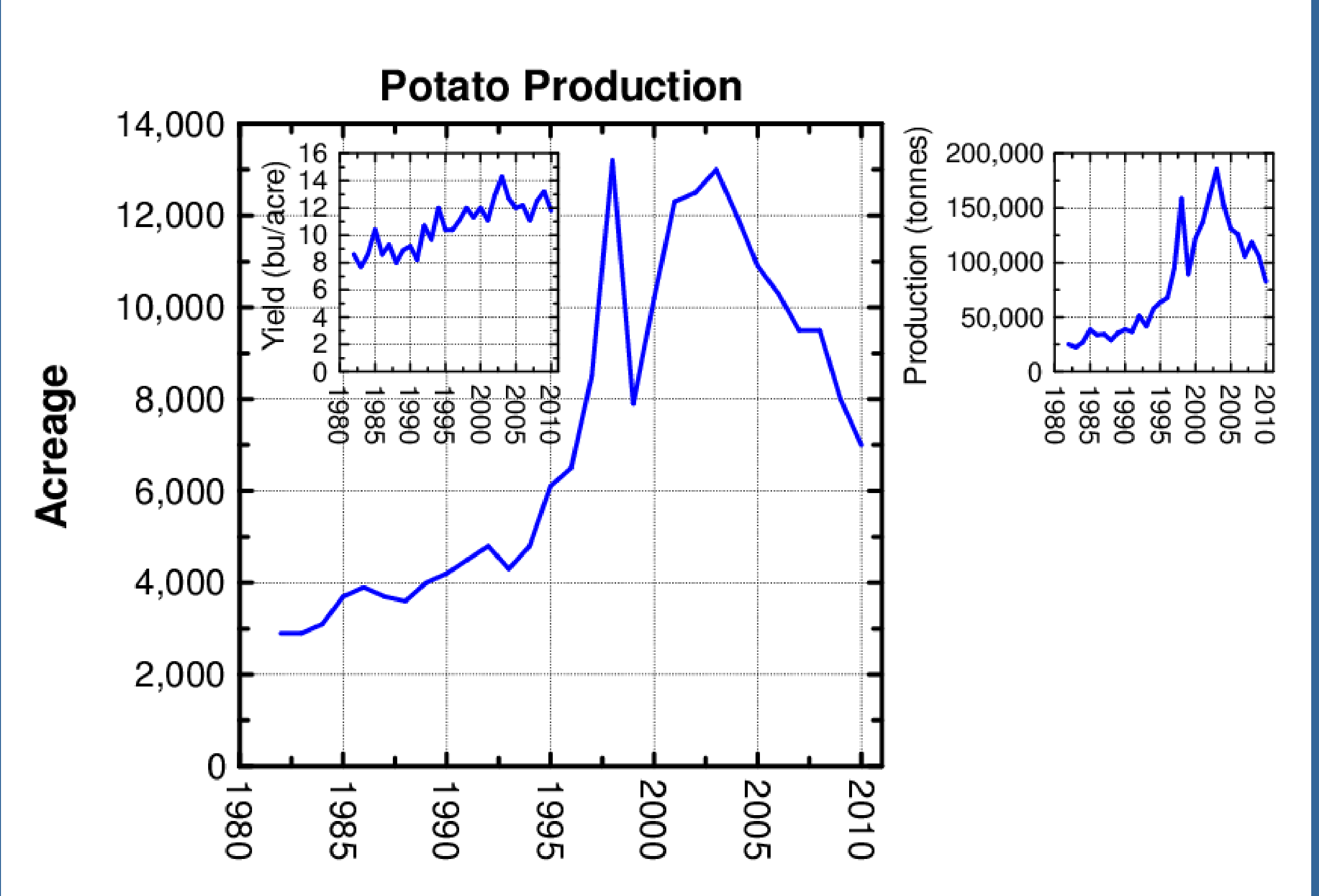

potato acreage/production increased exponentially between the early 1980s and the early 2000s, and has since steadily declined - yields have increased steadily s

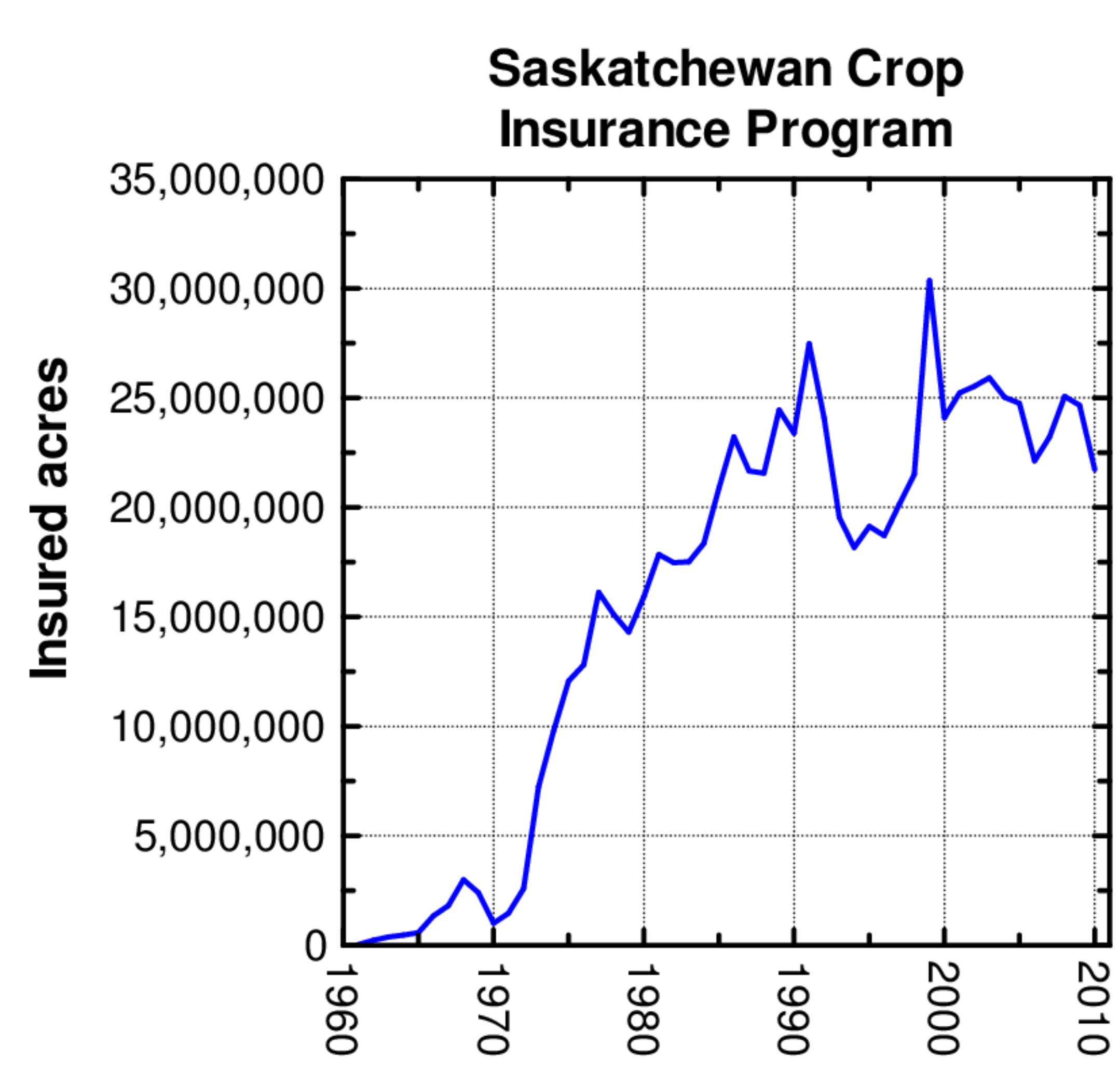

number of insured acres increased slightly during the 1960s, increased rapidly during the 1970s and 1980s, and has since stabilized
Results and Discussion

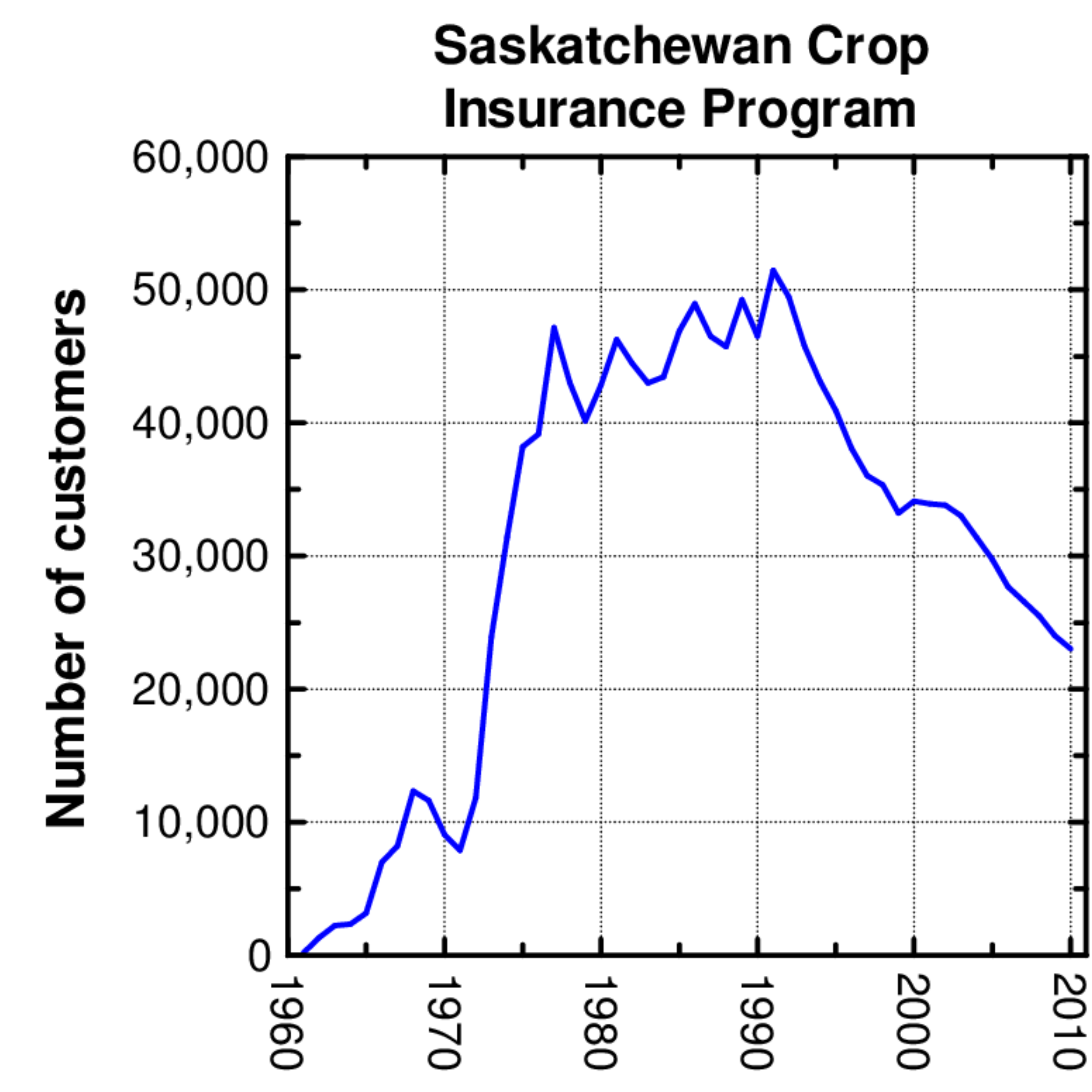

number of crop insurance customers increased steadily during continued to since declined substantially and steadily to the pry 1990, and

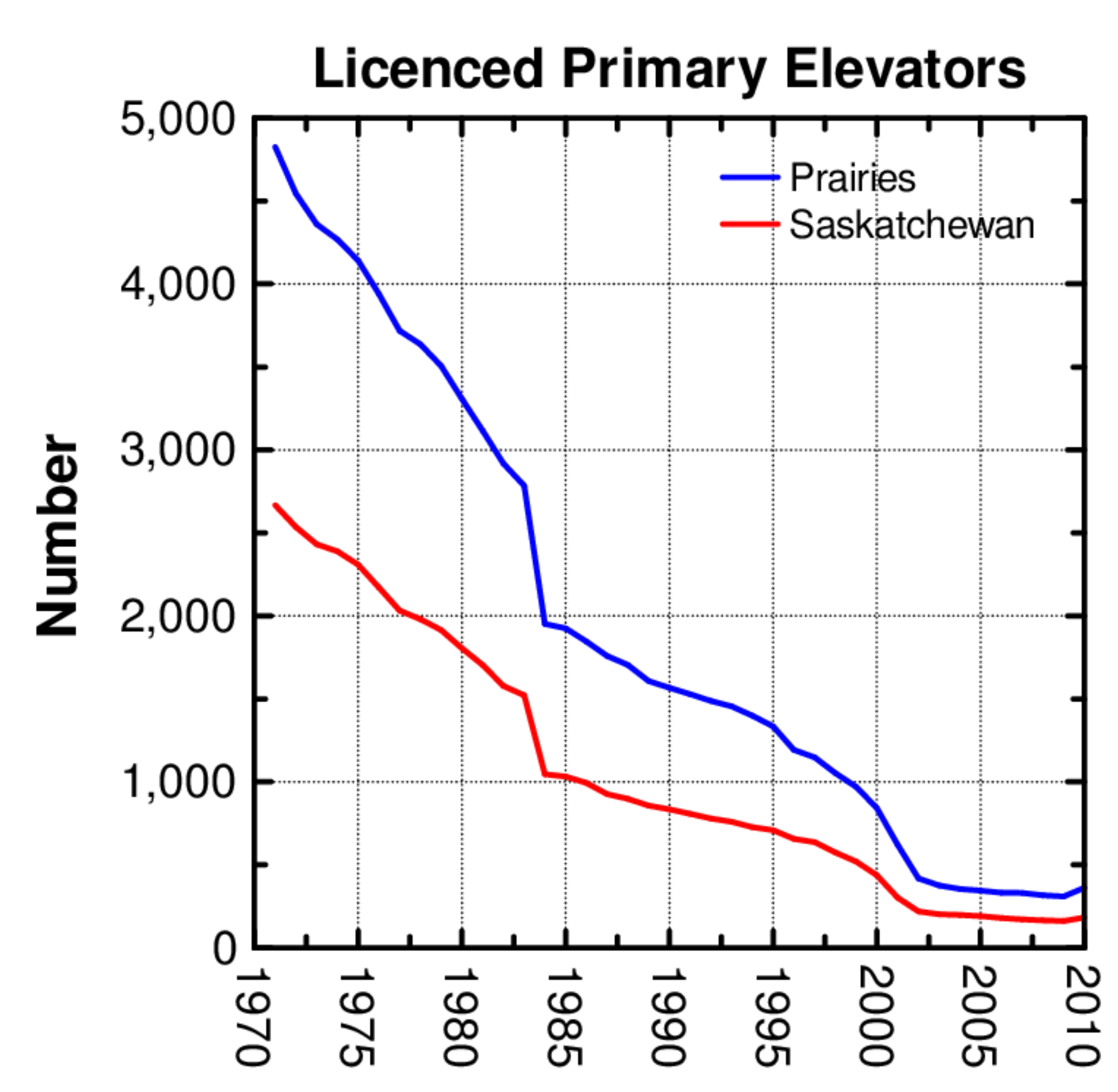

- he number of licensed primary elevators on the prairies, and

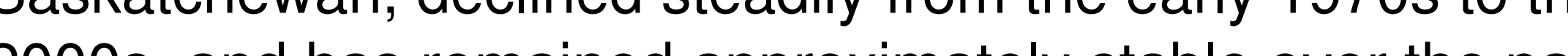
half-decade 


\section{Time Trends for Agricultural Crop Production in Saskatchewan, Canada: 1905-2011 SIAST}

\section{Sierra Rayne and Kaya Forest ${ }^{\mathrm{b}}$}

a Chemologica Research, PO Box 74, 318 Rose Street, Mortlach, Saskatchewan, Canada, SOH 3E0; e-mail: rayne.sierra@gmail.com

b Department of Environmental Engineering, Saskatchewan Institute of Applied Science and Technology, Palliser Campus, PO Box 1420,600 6th Avenue NW, Moose Jaw, Saskatchewan, Canada, S6H 4R4; e-mail: kaya.forest@siast.sk.ca

\section{Results and Discussion}

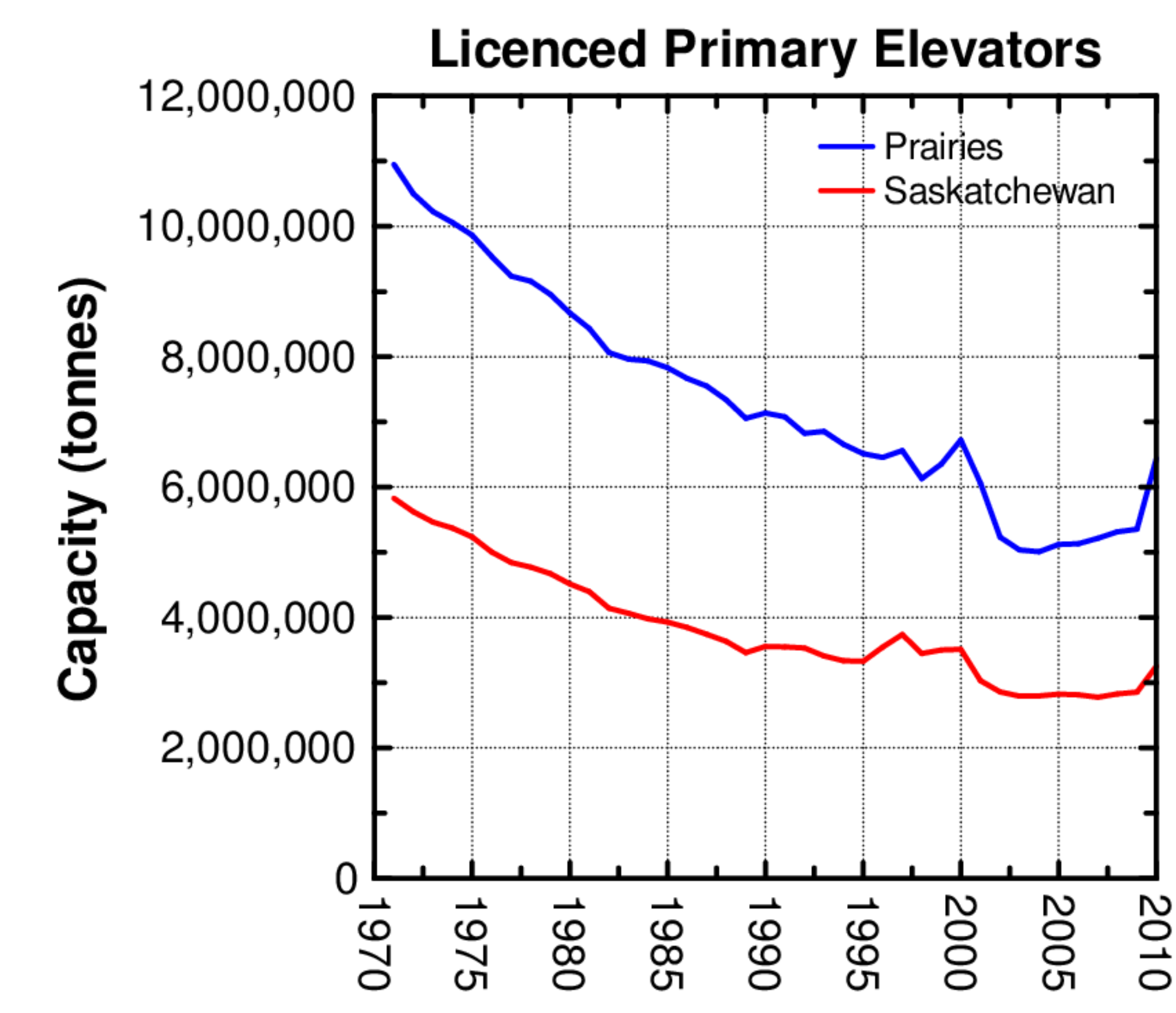

the capacity of licensed primary elevators on the prairies, and in Saskatchewan, declined steadily from the early 1970 s to the mid2000s, and has remained approximately stable over the past
half-decade (with evidence of a slight increase over the past half-decade (

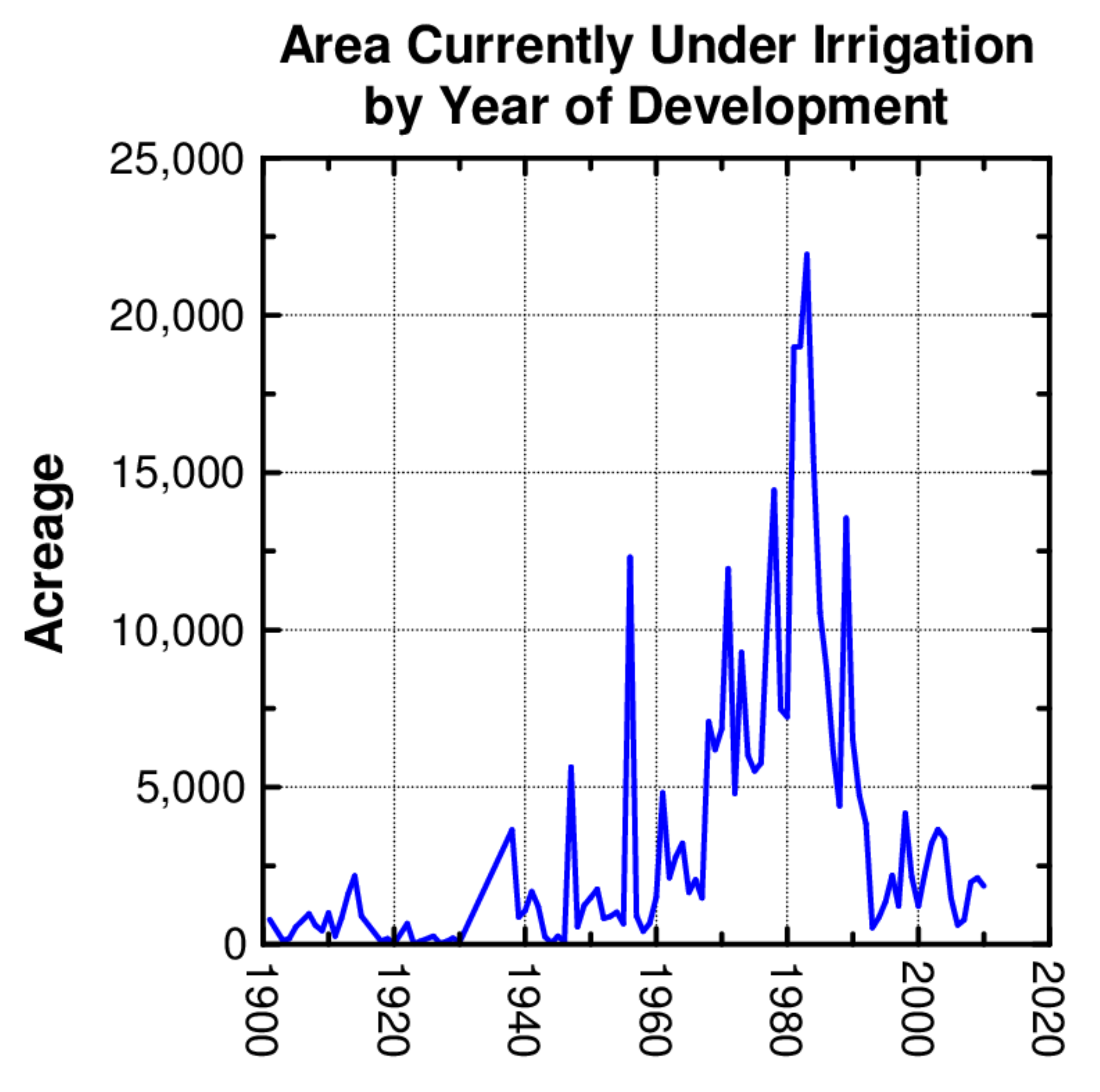

most inigation development (by area) occurred between the

1960 s and late 1980 s

\section{Results and Discussion}
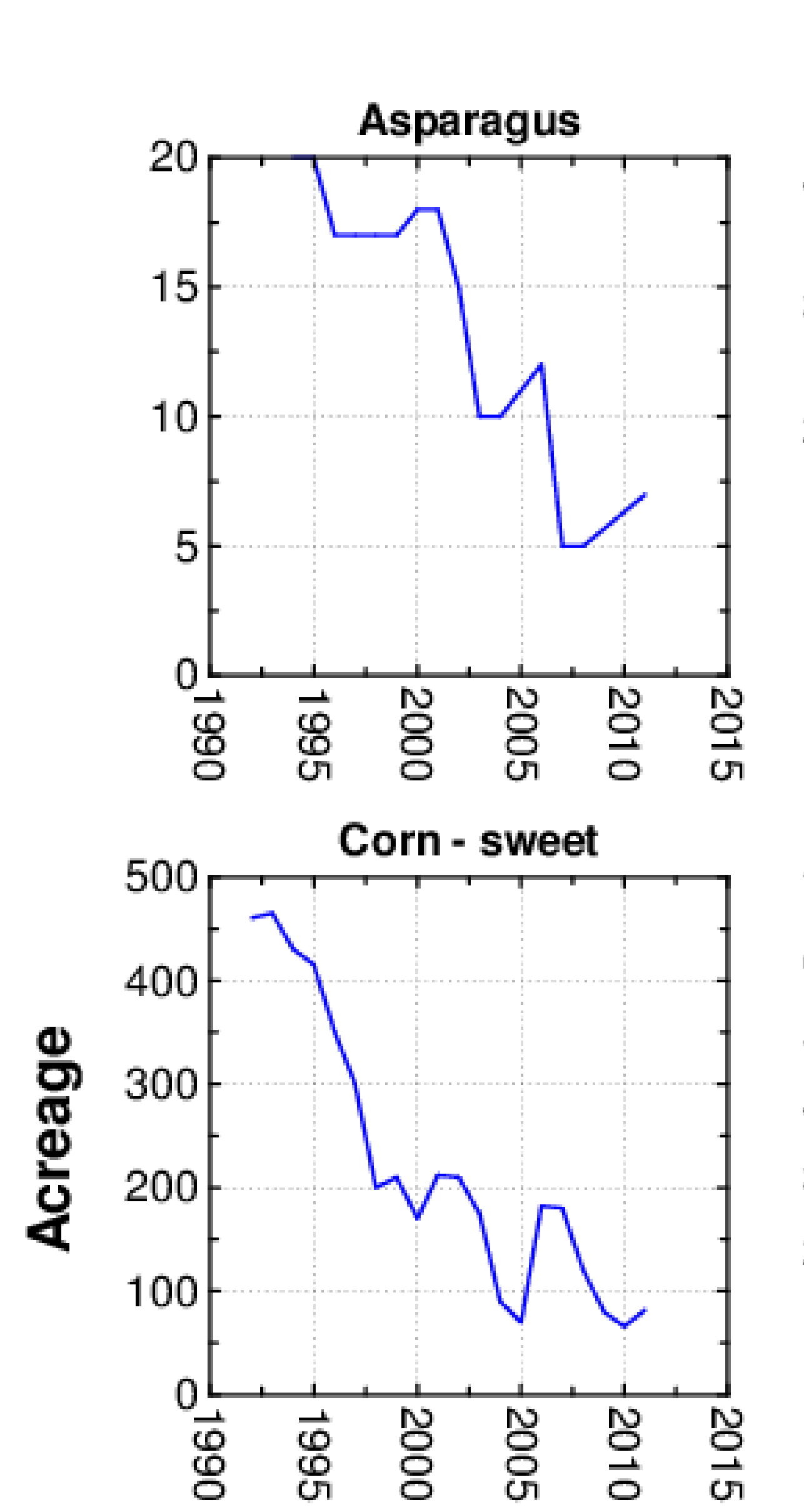

Beans - green or wax
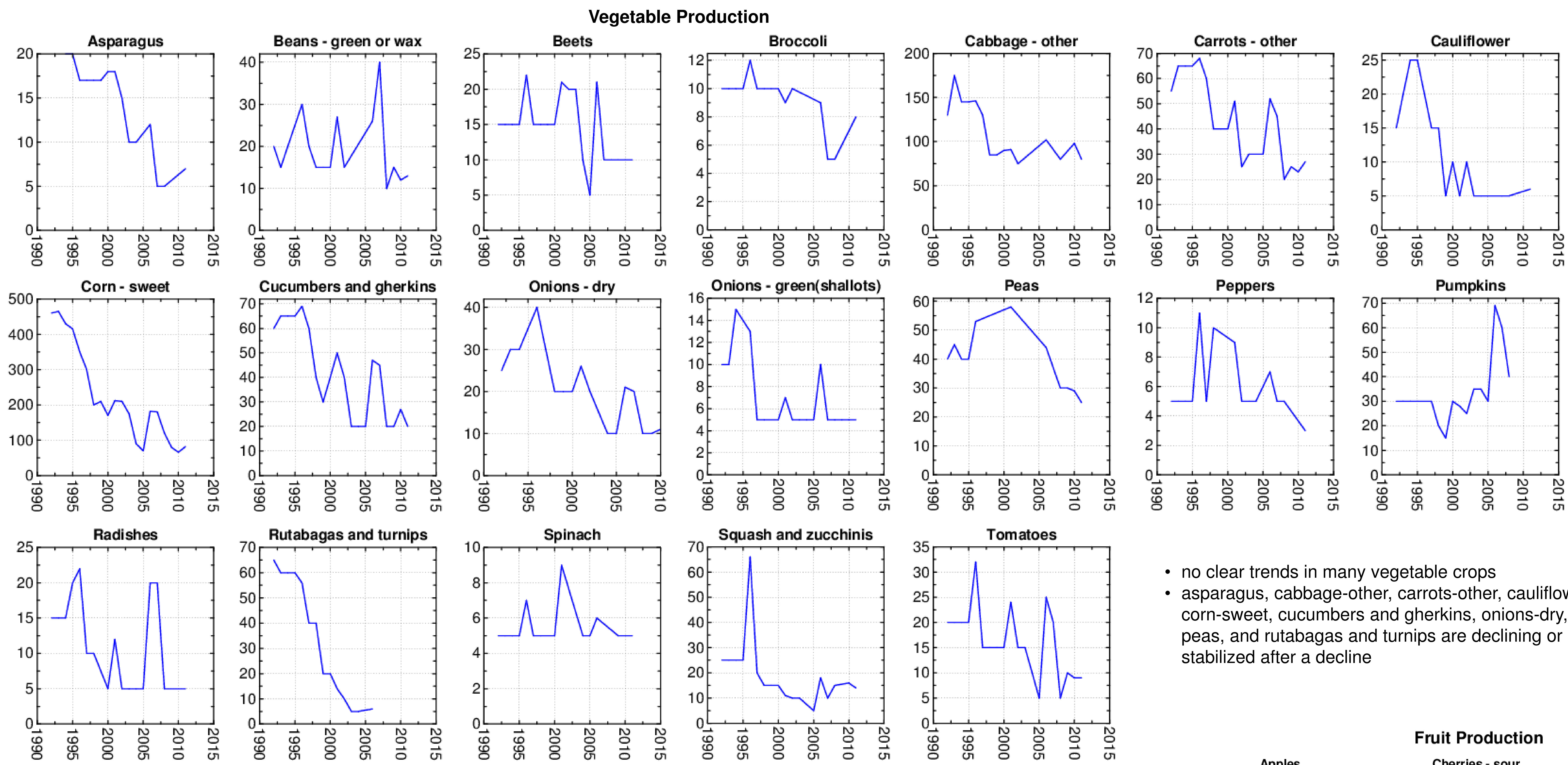
Area Under Irrigation,
by Type of Irrigation

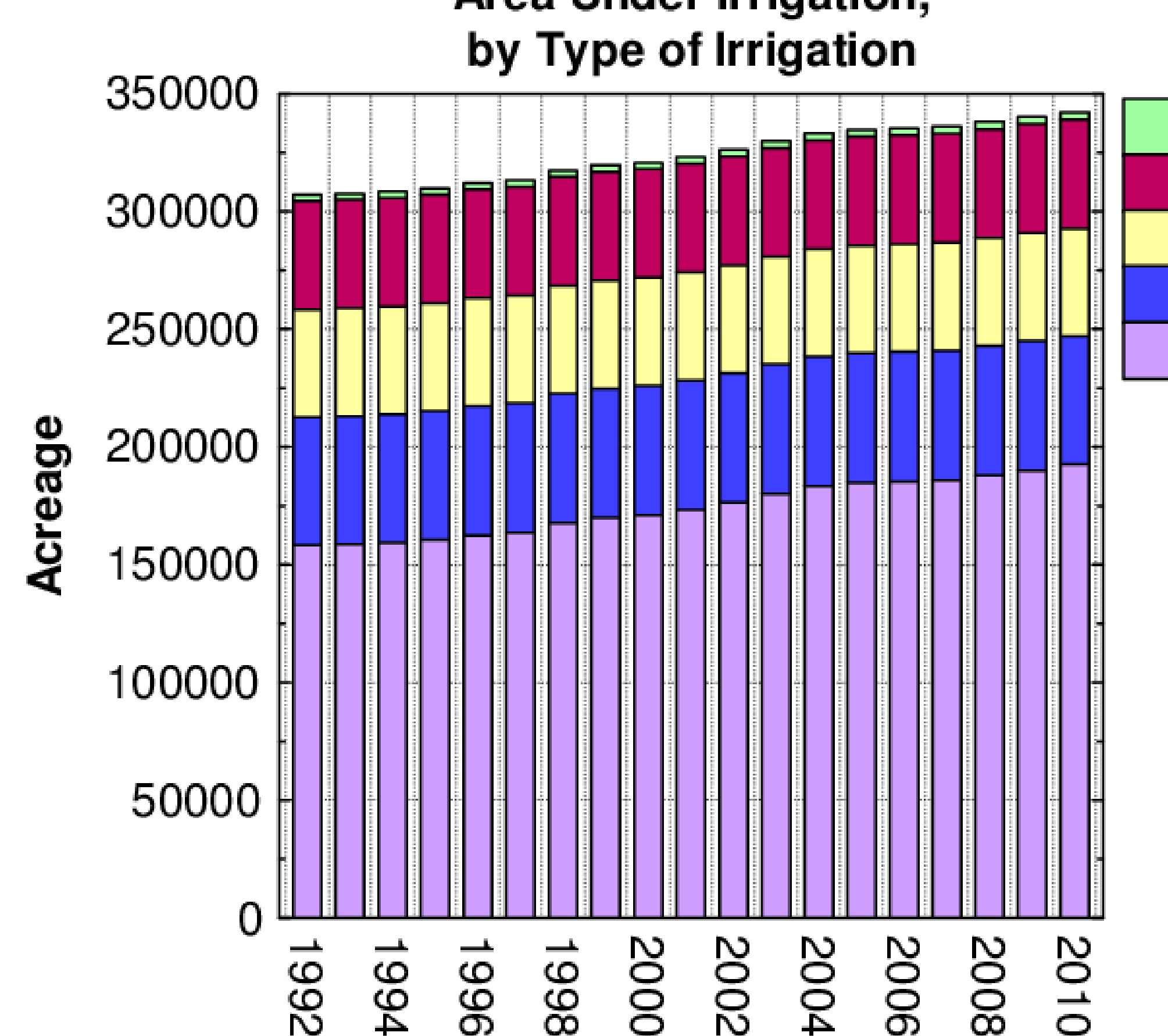

her Misc Backflood Surface
Sprinkler

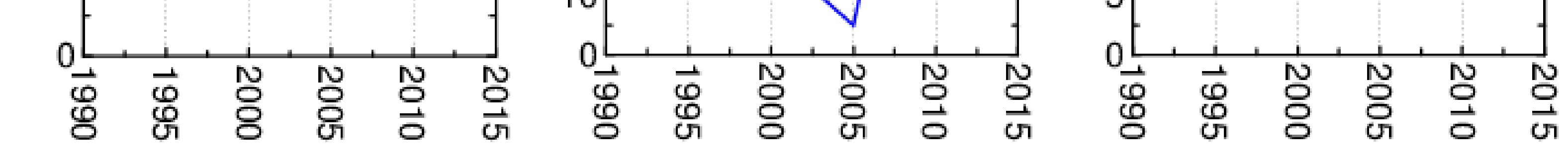

no clear time trend for raspberry acreage

- acreage for sour cheries and saskatoon ber

strawberry production increased slightly during the early 1990 . - acreage for th for apples and plums/prunes has been erratic has since either declined sharply (plums and prunes) or stabilized with high year-to-year variability (apples) - the early iggos

growth over this time has been via

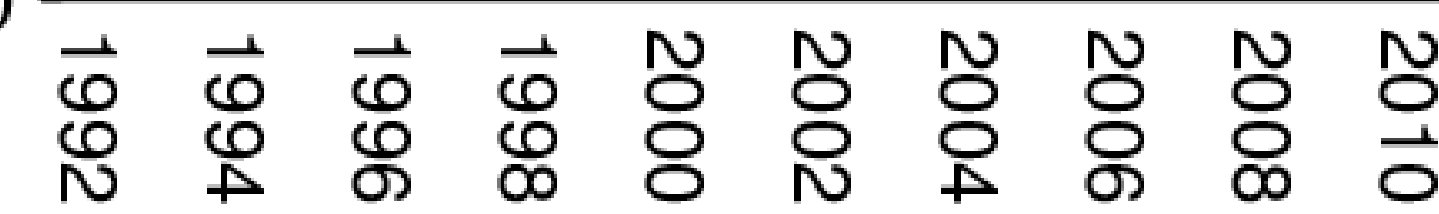

